\title{
Simulation of Crop Growth and Productivity using Simulation Model for Short Duration Rice
}

\author{
Ravikant Chandrvavanshi $^{1}$, G. Kar $^{2}$, Sonam Upadhyay ${ }^{3}$, \\ Parshottam Kumar Sinha $^{4^{*}}$ and Rohit ${ }^{5}$ \\ ${ }^{1}$ Krishi Vigyan Kendra Guna, M. P., India \\ ${ }^{2}$ Indian Institute of Water Management, Bhubaneswar, India \\ ${ }^{3}$ Department of Extension, JNKVV Jabalpur, M. P., India \\ ${ }^{4}$ Krishi Vigyan Kendra Kawardha, C. G., India \\ ${ }^{5}$ Department of Plant Breeding, IGKV Raipur, C. G., India \\ *Corresponding author
}

\section{A B S T R A C T}

Keywords

Simulation model,

Rice, CERES-Rice,

Crop growth models, DSSAT

Article Info

Accepted:

15 November 2019

Available Online:

10 December 2019
An experiment was conducted to study crop growth modeling at the paddy field of ICAR- Indian Institute of Water Management during Kharif 2016. The CERES-Rice model of DSSAT 4.5 was used to simulate crop growth and yield; Validation results showed that model predicted number of days to flowering with the RMSE values of 0.98. Four days difference was recorded between observed and simulated days to flowering in different varieties. The model simulated number of days from planting to physiological maturity with RMSE of 0.65 . LAI was simulated with RMSE of 0.38 for this cultivar. There was a good agreement between observed and simulated grain yield with RMSE of 0.35 the simulation of total crop biomass at harvest was also correlated with RMSE of 3.41.

\section{Introduction}

The decision support system for agrotechnology transfer (DSSAT) was originally developed by an international network of scientists, cooperating in the International Benchmark Sites Network for Agrotechnology Transfer project (IBSNAT, 1993; Tsuji, 1998; Uehara, 1998; Jones et al.,
1998), to facilitate the application of crop models in a systems approach to agronomic research. Its initial development was motivated by a need to integrate knowledge about soil, climate, crops, and management for making better decisions about transferring production technology from one location to others where soils and climate differed. The DSSAT helps decision-makers by reducing 
the time and human resources required for analyzing complex alternative decisions (Tsuji et al., 1998). Rice (Oryza sativa L.) is indispensable diet to more than a half of the world's population and one of the most important rapidly growing food crops cultivated around the world (Simonds et al., 1999). Rice plays a highly significant role in the daily diet of thousands of millions of Asian's, Latin American's and African's people. In south Asia, in particular, rice is providing an average of $32 \%$ of the total calorie uptake (Maclean et al., 2002).

In developing countries such as India, rice supports huge population as the key source of nutrition. In Asia, the area of rice paddies in this region is about $87 \%$ of the world's total rice cultivated area and about $80 \%$ of it is grown under flooded conditions. India produces 106.19 million tons of rice a year from 44 million hectares of land (FAOSTAT, 2013). Impacts of climate change on Agriculture will be one of the major deciding factors influencing the future food security of mankind on earth. Since rice is the staple food of India, it is essential to identify the impacts of climate change on rice yield to increase the country's rice production. Climatic factors such as temperature, rainfall, atmospheric $\mathrm{CO} 2$ and solar radiation are important parameters to rice production (Nyangau et al., 2014). The average daily maximum temperature and rainfall pattern will be changed as a result of increasing concentrations of $\mathrm{CO} 2$ and other greenhouse gases in atmosphere. These changes have become the most important considerations for rice production (Dharmarathna et al., 2011). Increasing trend of daily maximum temperature may decrease the rice spikelet fertility, which affects for reduction of the yield while the increasing trend of atmospheric $\mathrm{CO} 2$ concentration could increase the rice yield (Dharmarathna et al., 2012). Khurda district is one of the rice cultivation districts in Odisha and have a good potential for rice cultivation. Most of the farmers in this area cultivate improved rice varieties but their yield is always lower than the potential yield due to the different level of management practices and the variation of climatic conditions. Yield gap can be increased in the future due to climate change especially if current agricultural practices are continued (Basak et al., 2012). Understanding rice production in relation to weather changes is of great importance to boost food productivity Conducting the field experiments for identify impacts of climate change on rice cultivation will take long time period. DSSAT is a popular crop model that is used worldwide for modeling growth and yield of 30 different crops including rice under given soil and daily weather conditions. For future yield prediction it is required to calibrate and validate the DSSAT model with adjusting the cultivar genetic coefficients. Validated DSSAT model can be used to predict the future rice yields with future weather conditions and find the suitable adaptation measures for increase the yield (Jones et al., 2013). These tools can reduce the need for expensive and timeconsuming field trials and could be used to analyze yield gaps in various crops including rice (Pathak et al., 2005). Therefore this study was conducted to identify the changes of rice yield and growth in Khurda district under changing climate using DSSAT model.

\section{Materials and Methods}

The Decision Support System for Agrotechnology Transfer (DSSAT) was originally developed by an International Network of Scientists, cooperating in the International Benchmark Sites Network for Agrotechnology Transfer project (IBSNAT, 1993; Tsuji, 1998; Uehara, 1998; Jones et al., 1998) to facilitate the application of crop models in a systems approach to agronomic research. 
Crop growth models integrate the effects of soils, weather, management, genetics and pests on daily growth and can be used to gain insight into spatial yield variability. Among the numerous crop growth models the most widely used are the Decision Support for Agrotechnology Transfer (DSSAT) models, which were designed to stimulate growth, development and yield of a crop growing on a uniform area of land, as well as the changes in soil water, carbon, and nitrogen that take place under the cropping system over time.

DSSAT has been in use for the past 15 years by researchers all over the world for a variety of purposes, including crop management climate change impact studies, sustainability research, and precision agriculture and is well validated for a number of regions and crops. In the DSSAT family modules are included which simulate the growth of 16 different crops, including maize, soybeans, wheat, rice, and others. DSSAT are uses common modules for soil dynamics and soil-plant-atmosphere interactions regardless of the plant growth module selected.

\section{Inputs data required to run the simulation model}

The input data files required to run the model pertain to weather, soil genotype characteristics (Crop and cultivars) and experiment details (crop management). The experiment performance file is also used as input, if the simulated results are to be compared with data recorded in a particular experiment.

To run the model, a file containing information about all the available experiment provided to the model (EXP.LST) during the all-available experiment list would appear as a menu from which the user can select an experiment for simulation. The different input files are followed.

\section{Weather data file (WTH.)}

It contains daily weather data on maximum temperature, minimum temperature, total solar radiation and rainfall for the crop period. Daily weather data of the year 2016 were collected from ICAR-IIWM. Daily weather data as stated above includes the parameter of temperature (maximum and minimum), rainfall, and solar radiation.

\section{Preparation of weather files for the simulation model}

Simulation model requires weather data to be stored in format, which is compatible with the model weather data were arranged in a specific format of DSSAT 4.6 and were given the file extension of $W T H$. Data.

In DASST 4.6 uses used weather parameters in a sequence of Julian day solar radiation, maximum and minimum temperature and rainfall. The specific format of the DSSAT weather file has been given in table format (Table 1).

\section{Soil data file (FILES)}

The soil file contains soil information about all the sites encountered by CERES. To run the model one can either selected a representative to one from this file or simply add soil information to this files needed. Soil data includes soil texture, soil local classification, soil family CSC system, soil depth $(\mathrm{cm})$, color (moist), albino (fraction), evaporation limit $(\mathrm{cm})$, drainage rate (fraction day), run off curve number, mineralization factor (0 to 1sclae), photosynthesis factor (0 to 1) scale, $\mathrm{PH}$ in buffer determination method, amount (\%) and determination method of nitrogen, phosphorus and potassium. The model also requires horizon wise data such as, number of horizons, thickness of horizon (cm), field capacity (fraction), cultivating 
point (fraction), air-dry level (fraction), lower limit drained $\left(\mathrm{cm}^{-3} \mathrm{~cm}^{-3}\right)$, organic carbon $(\%)$, $\mathrm{pH}$ in water \& buffer, cation exchange capacity $\left(\mathrm{C} \mathrm{mol} / \mathrm{kg}^{-1}\right)$, root growth factor $(0.0$ to 1.0). Some information were collected from The all information was obtained from the experimental site and some were obtained from published literature.

\section{Crop Data}

For this study Khandagiri Variety was selected for the study area. The minimum data sets for were planting date; planting density, row spacing, planting depth, irrigation and fertilizer applications etc. and intercultural operation collected based on active experiments.

\section{Cultivars data file (FILEX)}

This file contains the cultivars genetic coefficient. Eight genetic coefficients are required for describing the various aspects of performance of a particular genotype: -P1, P2O, P2R, P5, G1, G2, G3 and G4.

The first four coefficients are related to phenological development and last four related to growth and grain development aspects of the rice crop. The details on these genetic coefficients are described below: -

P:- Time period (expressed as growing days) [GDD] in 0oc over as a base temperature of $\left(100^{\circ} \mathrm{C}\right)$ from seeding emergence during which the rice plant is not responsive to change in photoperiod of the plant. This period is also referred to as the basic vegetative phase of the plant.

P2O:- Critical photoperiod of the longest day length (in hours) at which the development occurs at a maximum rate. At values higher than p20 development rate is slowed hence there is a delay owing to longer day lengths. P2R:- extent to which phase development leading to panicle initiation is delayed. (Expressed as GDD in 0c for each hour increase in photoperiod above p20.

P5:- time period in GDD $\left({ }^{\circ} \mathrm{C}\right)$ from beginning of grain filling (3-4 days after flowering) to physiological maturity with a base temperature of $90^{\circ} \mathrm{C}$.

G1:- potential spike let no. Coefficient as estimated from the no. Spike let per $g$ of main culms dry weight is less lead blades and sheaths plus spikes of anthesis a typical value is 55 .

G2:- single grains a right (g) under ideal growing conditions i.e. Non-limiting light, water nutrients and in the absence of pest and diseases.

G3:- Tillring coefficient (sealer value) relative to Pusa Basmati cultivar under ideal condition. Higher tillring cultivars would have a coefficient greater than 1.0.

G4:- temperature tolerance coefficient usually 1.0 for varieties growth in normal environment G4 for Japonica type rice growing in a warmer environment would be 1.0 or greater. Likewise, the G4 value for indicia type rice in very cool environment or season would be less than 1.0.

\section{Experiment performance file}

This contains the observed values of experimental performance of the crop, which can be used for comparison with the simulated outputs of the model runs. The information provided includes anthesis date, physical maturity, yield, grain weight, grain number, panicle number, maximum LAI and dry matter.

Different statistical indices were used for evaluation of simulation performance, including root mean square error (RMSE) 
(Wallach and Goffinet, 1987) and index of agreement ( $d$-value) (Willmott, 1982). The computed values of RMSE, normalized RMSE and $d$-value determine the degree of agreement between the predicted values with their respective observed values and a low RMSE value and d-value that approaches one are desirable. The RMSE was calculated according to Equation 1.

$R M S E=\frac{\left.\sqrt{\sum_{i}^{n}=1\left(\mathrm{P}_{\mathrm{i}}\right.}-\mathrm{0}_{\mathrm{i}}\right)^{2}}{\mathrm{n}}$

Where,

$P_{i}$ and $O_{i}$ refer to predicted and observed values for the studied variables, respectively. Normalized RMSE (RMSEn) gives a measure $(\%)$ of the relative difference of simulated versus observed data. The simulation is considered excellent with a normalized RMSE less than $10 \%$, good if the normalized RMSE is greater than 10 and less than $20 \%$, fair if the normalized RMSE is greater than $20 \%$ and less than $30 \%$ and poor if the normalized RMSE is greater than 30\% (Jamieson et al., 1991). The RMSEn (Loague and Green, 1991).

\section{Results and Discussion}

\section{Crop growth simulation using DSSAT model}

The CERES-Rice Model of DSSAT 4.5 was used to simulate crop growth and yield, which is a process-oriented, management-level model and is developed to predict the duration of growth, the average growth rates, and the amount of assimilating partitioned to the economic yield components of rice. The simulation processes of the model are dynamic and are affected by environmental and cultivar specific factors. The duration of growth for a particular cultivar, however, is highly dependent on its thermal environment and to some extent the photoperiod during floral induction. Therefore, the model requires input data, such as daily weather data, initial soil conditions, crop management and crop cultivar information. The daily weather data includes solar radiation, precipitation, maximum and minimum temperatures. Initial soil conditions involve drainage and runoff coefficients, initial soil, water, rooting preference factors, organic nitrogen and carbon contents. The output data for each model simulation run encompasses the results of simulated daily growth and development, carbon balance, soil water balance, nitrogen balance, and mineral nutrient aspects. Calibration of the models was done based on six genetic coefficients. The duration of each stage makes use of the concept of thermal time similar to some other model like ORYZA. The model was calibrated with the help of 2014 kharif data and validated with the experimental data of 2016.

\section{Cultivar genetic coefficients, calibration and validation of the model}

DSSAT 4.5 (CERES-rice) requires a set of six eco-physiological coefficients for simulation of phenology, growth and grain yield of rice crop. The genetic coefficients of different varieties were taken from Kar et al., (2009) and modified by repeated interactions until a close match between simulated and observed phenology, growth and yield was obtained.

The model was calibrated with the observed crop growth and yield data set of 2014, obtained from plots fertilized with $90 \mathrm{~kg} \mathrm{~N}$ $\mathrm{ha}^{-1}$ and validated with experimental findings of 2016. Different eco-physiological coefficients for simulation are given in Table 2. The cultivar 'Khandagiri' had value of 524 $\left({ }^{\circ} \mathrm{C}\right.$ day) and $402\left({ }^{\circ} \mathrm{C}\right.$ day) for $\mathrm{P}_{1}$ and $\mathrm{P}_{5}$ respectively. 
Table.1 Specific format of the DSSAT weather file

\begin{tabular}{|l|l|l|l|l|l|}
\hline $\begin{array}{c}\text { Daily } \\
\text { Data }\end{array}$ & Tmax $\left({ }^{\circ} \mathbf{C}\right)$ & Tmin $\left({ }^{\circ} \mathbf{C}\right)$ & $\begin{array}{c}\text { sunshine } \\
\text { hours } \\
(\mathbf{h r s})\end{array}$ & $\begin{array}{c}\text { Solar } \\
\text { radiation } \\
\left(\mathbf{M j} / \mathbf{m}_{2}\right)\end{array}$ & $\begin{array}{c}\text { Rainfall } \\
(\mathbf{m m})\end{array}$ \\
\hline & & & & & \\
\hline & & & & & \\
\hline & & & & & \\
\hline
\end{tabular}

Table.2 Genotype coefficients for different rice varieties computed through CERES-Rice model

\begin{tabular}{|c|c|}
\hline Genetic coefficients & Khandagiri \\
\hline $\begin{array}{l}\text { P1: Time period in growing degree days }\left(\text { base } 9^{\circ} \mathrm{C} \text { ) from }\right. \\
\text { emergence to end of juvenile phase }\end{array}$ & 524 \\
\hline $\begin{array}{l}\text { P2R: Photoperiod sensitivity (degree day delay per hour } \\
\text { increase in day length) }\end{array}$ & 109 \\
\hline $\begin{array}{l}\text { P5: Degree days (base } 9^{\circ} \mathrm{C} \text { ) from beginning of grain- } \\
\text { filling }(3-4 \mathrm{~d} \text { after flowering) to physiological maturity }\end{array}$ & 402 \\
\hline P2O: Critical photo period (hour) & 10.8 \\
\hline $\begin{array}{c}\text { G1: Potential spikelet number coefficient as estimated from } \\
\text { number of spikelets per } \mathrm{g} \text { main culm + spike dry weight at } \\
\text { anthesis (g) }\end{array}$ & 59 \\
\hline G2: Single dry grain weight $(\mathrm{g})$ & 0.024 \\
\hline G3: Tillering coefficient & 1 \\
\hline G4: Temperature tolerance coefficient & 1 \\
\hline
\end{tabular}

Table.3 Summary of observed and validated crop growth parameters

\begin{tabular}{|c|c|c|c|c|}
\hline Crop parameters & Unit & Observed & Simulated & cRMSE \\
\hline Anthesis & Days & 80 & 84 & 0.98 \\
\hline Maturity & Days & 98 & 101 & 0.65 \\
\hline Maximum LAI & & 5.29 & 5.10 & 0.56 \\
\hline Grain Yield & $\left(\mathrm{t} \mathrm{ha}^{-1}\right)$ & 2.74 & 2.95 & 0.35 \\
\hline Total Dry Biomass & $\left(\mathrm{g} \mathrm{m}^{-2}\right)$ & 1014 & 1135 & 3.41 \\
\hline
\end{tabular}

The model performed good in validation of growth, phenology, grain yield and biomass. Validation results showed that model predicted number of days to flowering with the RMSE values of 0.98 . Four days difference was recorded between observed and simulated days to flowering in different varieties. The model simulated number of days from planting to physiological maturity with RMSE of 0.65. Maximum LAI was simulated with RMSE of 0.38 for this cultivar. There was a good agreement between observed and simulated grain yield with RMSE of 0.35 . The simulation of total crop 
biomass at harvest was also well correlated with RMSE of 3.41. The Summary of observed and validated crop growth parameters are presented in Table 3.

Kumari Mamta (2008) also found similar pattern of the response in Pusa Basmati-1 when simulated with CERES-Rice model the anthesis with RMSE 1.53, maturity with RMSE 0.79, maximum LAI with RMSE 2.35, Grain yield with RMSE 0.36 and total dry biomass with RMSE was 3.08.

The calibration study demonstrates CERES Rice can be utilized to predict development (phenological stages) growth, yield and yield attributes. Field validation of the model indicates that simulated value were in good agreement with the observed. Sensitivity analyses showed that increase in temperature decreases the growth period, biomass production, yield, yield attributes of the rice crop but decrease in temperature increases the growth period, biomass production, yield and yield attributes.

Genetic coefficients required for the CERESRice v4.5 model for simulation of the growth and development of rice crop have been derived for rice cultivar Khandagiri. The model was calibrated with the help of 2014 kharif data and validated with the experimental data of 2016.

The present study has clearly showed the robustness of the DSSAT model of rice crop, to be valuable tool for predicting rice yield and identifying the critical phenophases which influence crop performance under varying climate conditions. therefore, the validated DSSAT model can be used for various applications such as prediction of crop growth, phenology, potential and actual yield, performance of rice under climate change conditions etc. The model may also to be used to improve and evaluate the current practices of rice crop growth management and in suggesting ways to enhance rice crop production, in any agroclimatic zone.

\section{References}

Dharmarathna WRSS, Weerakoon SB, Herath S, Rathnayaka UR, Weerakoon WMW., 2011. Application of Decision Support System for Agrotechnology Transfer (DSSAT) model to optimize irrigated paddy cultivation under changing hydro climate, Annual transactions of Institutions of Engineers, Sri Lanka. 207-211.

Jamieson, P.D., Porter, J.R. and Wilson, D.R., 1991. A test of the computer simulation model ARCWHEAT1 on wheat crops grown in New Zealand. Field crops research, 27(4), pp.337350.

Kar, G., Kumar, A. 2009 a. Surface energy fluxes and crop water stress index in groundnut under irrigated ecosystems. Agriculture and Forest Meteorology., (Elsevier), 146: 94-106.

Loague, K. and Green, R.E. (1991) Statistical and Graphical Methods for Evaluating Solute Transport Models: Overview and Application. Journal of Contaminant Hydrology, 7, 51-73.

Nyangau WO, Mati BM, Kalamwa K, Wanjogu RK, Kiplagat LK., 2014. Estimating rice yield under changing weather conditions in Kenya using CERES rice model. International Journal of Agronomy. vol 2014.

Pathak, H., C. Li, and R. Wassmann., 2005. Greenhouse gas emissions from Indian rice fields: calibration and upscaling using the DNDC model. Biogeosciences Discussions. 2(1). 77102.

Wallach, D. and Goffinet, B., 1987. Mean squared error of prediction in models for studying ecological and agronomic 
systems. Biometrics, pp.561-573.

Willmott, C.J., 1982. Some comments on the evaluation of model performance.
Bulletin of the American Meteorological Society, 63(11), pp.1309-1313.

\section{How to cite this article:}

Ravikant Chandrvavanshi, G. Kar, Sonam Upadhyay, Parshottam Kumar Sinha and Rohit. 2019. Simulation of Crop Growth and Productivity using Simulation Model for Short Duration Rice. Int.J.Curr.Microbiol.App.Sci. 8(12): 2081-2088.

doi: https://doi.org/10.20546/ijcmas.2019.812.246 